\title{
Removal of water hardness causing constituents using alkali modified sugarcane bagasse and coffee husk at Jigjiga city, Ethiopia: A comparative study
}

\author{
Adhena Ayaliew Werkneh ${ }^{1,}{ }^{*}$, Angaw Kelemework Abay ${ }^{1}$, Anbisa Muleta Senbeta ${ }^{2}$ \\ ${ }^{1}$ Department of Chemistry, College of Natural Science, Jigjiga University, PO. Box: 1020, Jigjiga, Ethiopia \\ ${ }^{2}$ Department of Food Science and Nutrition, College of Dryland Agriculture, Jigjiga University, PO. Box: 1020, Jigjiga, Ethiopia
}

\author{
Email address: \\ adhena1988@gmail.com (A. A. Werkneh)
}

\section{To cite this article:}

Adhena Ayaliew Werkneh, Angaw Kelemework Abay, Anbisa Muleta Senbeta. Removal of Water Hardness Causing Constituents Using Alkali Modified Sugarcane Bagasse and Coffee Husk at Jigjiga City, Ethiopia: A Comparative Study. International Journal of Environmental Monitoring and Analysis. Vol. 3, No. 1, 2015, pp. 7-16. doi: 10.11648/j.ijema.20150301.12

\begin{abstract}
Alkaline modified sugarcane bagasse and coffee husk were used for the adsorption of water hardness causing constituents $\left(\mathrm{Ca}^{+2}\right.$ and $\left.\mathrm{Mg}^{+2}\right)$. The water hardness sample was collected using polyethylene bottle from Jigjiga city drinking water supply, Ethiopia. The adsorbents were characterized using FTIR and BET surface area techniques. The concentration of the constituents were determined using AAS Spectroscopy. It was found that, using the ABC and ACHC as an adsorbent, the maximum sorption capacity obtained for $\mathrm{Ca}$ and $\mathrm{Mg}$ hardness adsorption are 46.8 and 37.35 , and 52.9 and $41.23 \mathrm{mg} \mathrm{g}^{-1}$ for $\mathrm{ACHC}$ and $\mathrm{ABC}$ respectively. Activated carbon filtration also depends on various parameters such as $\mathrm{pH}$, contact time, adsorbent dose, temperature and initial $\mathrm{Ca}$ and $\mathrm{Mg}$ ion concentrations. The maximum recovery of the adsorbed calcium and magnesium was achieved in less than 200 minutes leading to $78 \%$ and $73 \%$ respectively. After treating synthetic water solution simulating an actual water stream with the alkali-modified bagasse and coffee husk, total hardness of the treated sample meets the required standard for drinking water, below $60 \mathrm{mg} / \mathrm{L}$ of $\mathrm{CaCO}_{3}$. Therefore, $\mathrm{ABC}$ is more suitable for the removal of hardness ions than ACHC from drinking water; and are considered as effective low cost adsorbents.
\end{abstract}

Keywords: Water Hardness, Activated Carbon, Bagasse, Coffee Husk

\section{Introduction}

Quality of water is one of the most important natural resources of the world. It plays a vital role in the development of communities; hence a reliable supply of water is essential. It needs to be maintained all the time for human and industrial use. As for human consumption, quantity and quality of drinking water have been recognized as increasingly critical issues. Addressing the deterioration of water quality in developing countries, where an estimated one billion people lack access to potable quality water, is a primary motivating factor for many community development efforts and is a key component of the Millennium Development Goals [1]. The provision of safe water to the people is an urgent development priority of any country in the world [1], [2].

Most of the water resources should be treated for purification before consumption. In some countries, groundwater is the main safe drinking water resource [1]. In some cases, the resource does not satisfy to the desirable levels regarding their chemical properties, such as hardness, nitrate contamination, heavy metals, soluble iron, etc. [2]. Among them, water hardness can appear problematic in some cases; it can also be considered as an important aesthetic parameter. However, because public acceptance of hardness differs remarkably according to local conditions, a maximum acceptable level has not been defined. In general, water supplies with total hardness higher than $200 \mathrm{mg} / \mathrm{L}$ can be tolerated by consumers but are considered as poor resources; while values higher than $500 \mathrm{mg} / \mathrm{L}$ are not acceptable for most of the domestic consumptions [3], [4].

Recently, various methods including electro deionization process, electro membrane processes, capacitive deionization, membrane and fluidized pellet reactor, ion exchange process and adsorption have been studied for the removal of a wide variety of ionic and molecular species from various water 
streams, including those responsible for hardness (e.g. $\mathrm{Ca}^{+2}$ and $\mathrm{Mg}^{+2}$ cations). Amongst the developed processes, adsorption has been widely studied for the uptake of various ionic and molecular species from water [6]-[8].

In an effort to reduce the proportion of people without sustainable access to safe drinking water, there is a need to optimize the production of activated carbon from locally available wastes and apply it for water treatment in diverse communities. This has led to the development of alternative low-cost technologies such as activated sugar cane bagasse for the treatment of drinking water in the developing world. Research has also been focused on the indigenous production of water treatment chemicals using locally available raw materials [1]. Carbon adsorption offers significant advantages including low cost, availability, profitability, ease of operation and efficiency in comparison with conventional methods especially from economically and environmentally points of view [4],[5].

In countries with poor economic base, the high cost of importing the water treatment chemicals prevents consistently good drinking water quality being achieved in many cases. The activated carbon has been widely used worldwide as an effective filtration or adsorption material for removing chemical contaminants from drinking water. In most developing countries, the activated carbon is imported at high cost, limiting the quantities of safe drinking water available to the people. The high cost of importing the activated carbon puts a significant burden on the water treatment budget since foreign currency is scarce [6],[7]. The main aim of the study was to apply activated carbon prepared from coffee husk and bagasse wastes in drinking water treatment and assess the efficiency of the carbons in the purification of hardness of water as a function of operating parameters [3].

\section{Materials and Methods}

\subsection{Description of the Study Area}

Jigjiga is a city in eastern Ethiopia and the capital of the Somali Region of the country. The city is located in the Jigjiga Zone approximately $80 \mathrm{~km}(50 \mathrm{mi})$ east of Harar and $60 \mathrm{~km}$ (37 mi) west of the border with Somalia. The city has an elevation of 1,609 meters above sea level and are found with coordinates of $9^{\circ} 21^{\prime} \mathrm{N} 42^{\circ} 48^{\prime} \mathrm{E}$. The climate of Jigjiga is a subtropical highland climate (Köppen climate classification), with the influence of mountain climate, with hot and dry summers and cold winters. The temperature range of the city was between 25 and $29^{\circ} \mathrm{c}$. As of 2008, Jigjiga has about $34.1 \%$ of the total population has access to drinking water from underground water

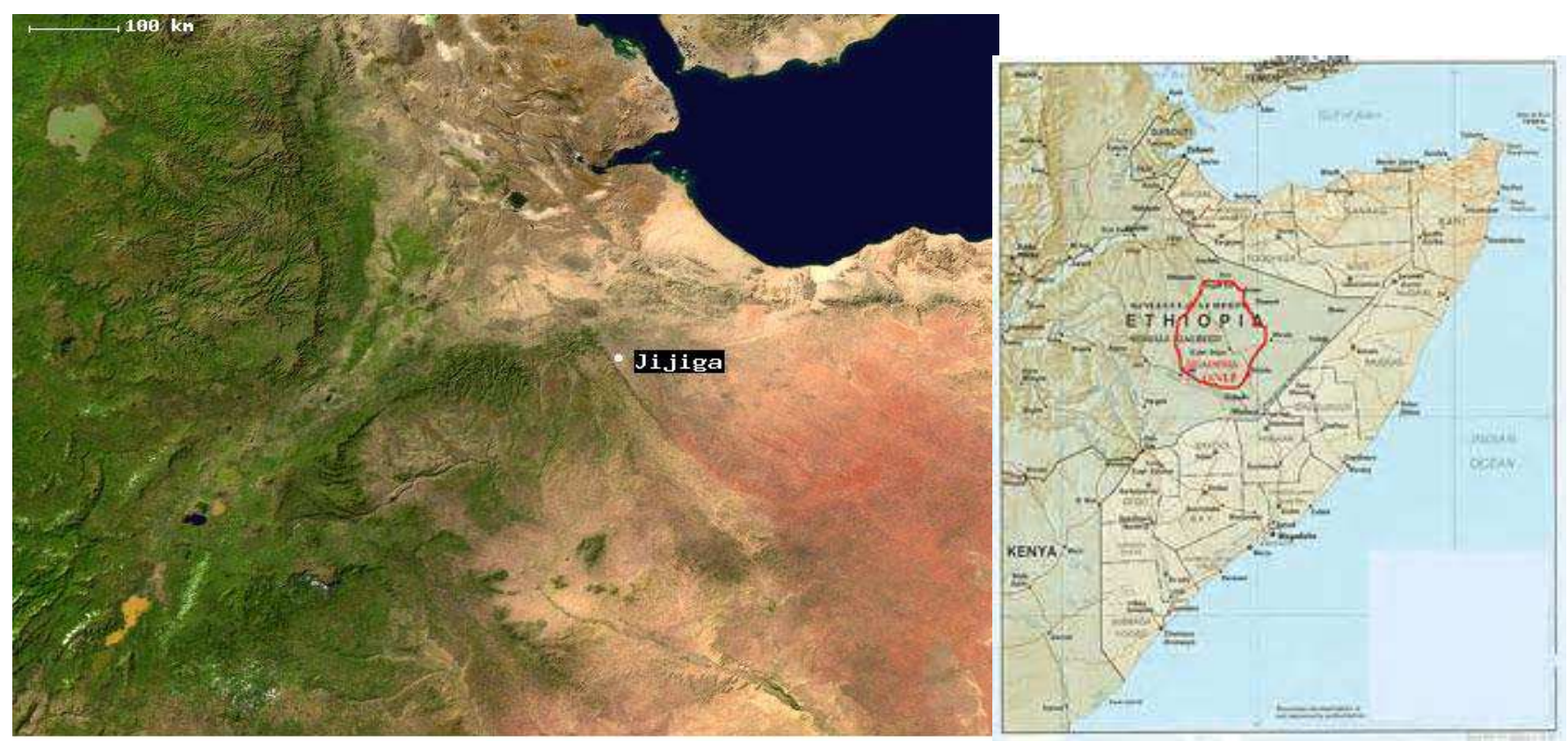

Figure 1.1. Map of the study area. 


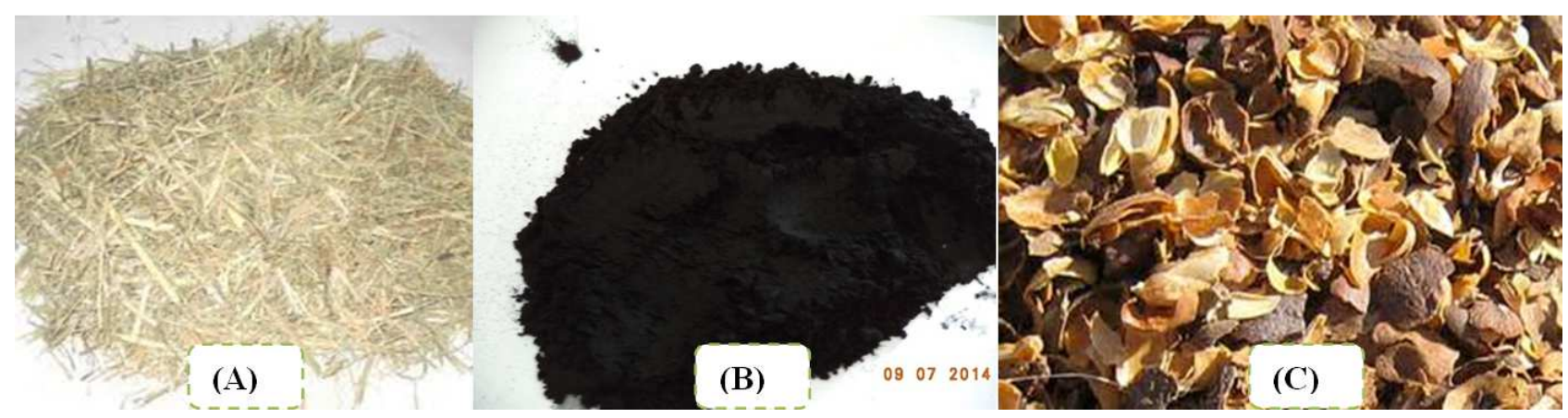

Figure 1.2. Shows (A) Raw sugarcane bagasse, (B) Alkali activated carbon, (C) Raw Coffee Husk.

\subsection{Chemicals and Solutions}

Apparatus and instruments: $\mathrm{pH}$ meter (MP 220, METTLER TOLEDO), FTIR spectrometer, AAS spectrophotometer (BUCK SCIENTIFIC MODEL VGP210, USA), Rotary Shaker (VRN - 480, GEMMY Orbit Shaker, Taiwan), Balance (OHAUS, E11140, Switzerland), Desiccators, Electrical mill (IKA-WERKE, M20 GMBH \& CO.KG, GERMANY), Filter Paper (Whatman 542, $90 \mathrm{~mm}$ diameter), Sieve no of different size (IMPAOT, UK), Deionizer, hot air Oven (OV150CGENL ABWIDNES, England).

\subsubsection{Reagents and Chemicals}

Analytical grade $\mathrm{CaCl}_{2}$ and $\mathrm{MgSO}_{4} .7 \mathrm{H}_{2} \mathrm{O}$ purchased from Avishkar LAB TECH CHEMICALS, LOT which were used as a model compound to stimulate the total hard water, Sulphuric acid $\left(\mathrm{H}_{2} \mathrm{SO}_{4}\right)$ purchased from Reagent chemical service limited Company, Runcorn Cheshire used to activate bagasse and coffee husk, Sodium hydroxide $(\mathrm{NaOH})$ from Avishkar LAB TECH CHEMICALS, LOT used to adjust the $\mathrm{pH}, \mathrm{HCl}$ from Reagent chemical service limited Company, Runcorn Cheshire used for titration, Sodium Chloride $(\mathrm{NaCl})$ purchazed from TITAN BIOTECH LIMITED, BHIWADI which was used for titration in Sear's surface area analysis. All experiments were conducted according to the standard methods for the examination of water and wastewater [21].

\subsubsection{Sampling and Sample Collections}

Tap ground water samples were collected in clean $1000 \mathrm{ml}$ plastic bottles. The containers were first washed with deionized water, and then several times with the sample water before collection in order to avoid any contamination. The samples were then carried in ice-packed coolers to the laboratory for analysis within 24 hours.

\subsection{Collection and Preparation of Adsorbent}

Raw Sugarcane Bagasse and coffee husk were collected from Wonji sugar factory and coffee refinery S. C in Ethiopia, which are collected as a waste. The samples were soaked for 24 hours and washed with distilled water before use in order to remove any impurities. Raw sugar cane bagasse sample was boiled for $30 \mathrm{~min}$ to remove remain soluble sugars. They were kept in drying oven maintained at $105^{\circ} \mathrm{C}$ for a period of 24 hours. The dried materials were grounded with electrical grinder to get the desired particle size of $500 \mu \mathrm{m}$. Then, they were treated with concentrated sodium hydroxide, $2 \mathrm{M}$ $\mathrm{NaOH}$ for 24 hours at room temperature with the ratio of 1:1 (base to carbon ratio) then stirred for $30 \mathrm{~min}$ and left for overnight. The purposes of treating carbon using $2 \mathrm{M} \mathrm{NaOH}$ were to create a suitable environment for its ring opening which increase the number of adsorption sites. Finally, the treated carbons were washed with distilled water to remove excess bases and any other soluble substances before the sample were dried in Furnace and adjusted its $\mathrm{pH}$ to about 6.5. These materials are referred as activated Sugarcane bagasse and coffee husk. All experiments were conducted according to the standard methods for the examination of water and wastewater.

\subsection{Batch Filtration Experiments}

All experiments were conducted in batch mode in $250 \mathrm{~mL}$ conical flasks. Several operating parameters including $\mathrm{pH}(2-$ $10)$, temperature $\left(10-50{ }^{\circ} \mathrm{C}\right)$, adsorbent mass $(2-10 \mathrm{~g} / \mathrm{L})$, initial calcium and magnesium concentrations $(40-120 \mathrm{mg} / \mathrm{L})$ and contact time (40-120 minutes) were investigated. Optimized adsorption times for modified adsorbents were first examined by varying the contact time at room temperature, $\mathrm{pH}=6.0$ and for an adsorbent mass of $2 \mathrm{~g}$ per liter of solution. For this purpose, $2 \mathrm{~g}$ of adsorbent were added to $1 \mathrm{~L}$ of solution in a conical flask containing $\mathrm{Ca}^{+2}$ or $\mathrm{Mg}^{+2}$ cations at a concentration in the range of 40 to 120 $\mathrm{mg} / \mathrm{L}$. The mixture was then shaken at $200 \mathrm{rpm}$.

The removal efficiency (\%R) and sorption capacity (Qe) was determined as follows (Eq. 1 and 2):

$$
\begin{gathered}
\mathrm{R}(\%)=[(\mathrm{Ci}-\mathrm{Ce}) / \mathrm{Ci}] \times 100 \\
\mathrm{Q}_{\mathrm{e}}(\mathrm{mg} / \mathrm{g})=[(\mathrm{Ci}-\mathrm{Ce}) / \mathrm{m}] \mathrm{V}
\end{gathered}
$$

Where, $C_{o}$ and $C_{f}$ are the initial and final concentration of metal in solution ( $\left.\mathrm{mg} \mathrm{l}^{-1}\right), \mathrm{V}$ is the volume of solution (1) and $\mathrm{m}$ is the mass of sorbent $(\mathrm{g})$.

After investigation of the effect of the contact time and the initial ion concentration, the effects of $\mathrm{pH}$ and adsorbent mass were examined. The effect of temperature was then investigated in the optimal conditions for $\mathrm{pH}$, adsorbent mass and contact time, for three initial concentrations of $\mathrm{Ca}^{+2}$ or $\mathrm{Mg}^{+2}$ cations $(60,120$ and $180 \mathrm{mg} / \mathrm{L})$. All the experiments had performed in duplicate and the mean values were 
reported.

Analysis of the Adsorbate Solution:

Spectrophotometric measurements were carried out using Atomic Absorption spectrophotometer using calcium and magnesium hollow-cathode lamp at respective wavelengths and an air/acetylene flame with strict adherence to standard calibration guidelines.

Characterization of Adsorbents: In order to understand the mechanism of the sorption, large quantities of work was done to investigate the influence of the sorption process using different kinds of techniques. Fourier Transform Infrared (FTIR) Spectroscopy analysis was conducted at Ethiopia Pharmaceutical Factory, Addis Ababa, Ethiopia which is used to asses functional groups of the adsorbents.

Determination of BET surface area: The specific surface areas of the adsorbents were determined using the Sear's method (1956). For this $1.5 \mathrm{~g}$ of modified adsorbents were acidified with $0.1 \mathrm{M} \mathrm{HCl}$ to $\mathrm{pH}$ value of 3-3.5. The volume in the beaker was made to $150 \mathrm{ml}$ with distilled water after addition of $10.0 \mathrm{~g}$ of $\mathrm{NaCl}$. Titration was then carried out with $0.1 \mathrm{M}$ of $\mathrm{NaOH}$ to $\mathrm{pH}$ value of 4.0 and then to $\mathrm{pH}$ value of 9.0. The volume $\mathrm{V}(\mathrm{ml})$, required to raise the $\mathrm{pH}$ from 4.0 to 9.0 was noted and the specific surface area was computed from the following equation [20].

$$
\mathrm{S}\left(\mathrm{m}^{2} / \mathrm{g}\right)=32 \mathrm{~V}-25
$$

Determination of the zero point charge: The zero point charge was determined using $0.01 \mathrm{M}$ solution of $\mathrm{NaCl}$ as an electrolyte and by adding $0.1 \mathrm{M}$ solutions of $\mathrm{HCl}$. For this purpose, the $\mathrm{pH}$ of eight beakers containing $50 \mathrm{~mL}$ of electrolyte was set to the desirable values in the range of 2 to 12. Then 2 gram of adsorbent was added into each beaker and shaken for 48 hours. After completion of the reaction, the adsorbent was filtered and the final $\mathrm{pH}$ of each beaker was measured. By plotting the initial $\mathrm{pH}$ versus the $\mathrm{pH}$ after 48 hours of agitation, the zero point charges of the adsorbents were determined, which were found to be 6.5 for modified bagasse and coffee husk.

\subsection{Regeneration of the Spent Adsorbents}

Regeneration tests for saturated modified adsorbents were carried out by adding $2 \mathrm{~g} / \mathrm{L}$ of spent adsorbent in $2 \mathrm{M}$ solution of $\mathrm{NaOH}$. For adsorbent saturation, $2 \mathrm{~g} / \mathrm{L}$ of adsorbent were let in contact with $250 \mathrm{~mL}$ solution containing $100 \mathrm{mg} / \mathrm{L}$ calcium or magnesium and stirred at $200 \mathrm{rpm}$ until equilibrium time was reached (120 minutes). The spent of the adsorbents were filtered, washed and dried at $55{ }^{\circ} \mathrm{C}$ for $24 \mathrm{~h}$. The dried spent adsorbents were let in contact of $2 \mathrm{~N} \mathrm{NaOH}$ for 2 hours; then filtered, washed several times with deionized water and dried at $55{ }^{\circ} \mathrm{C}$ for 24 h. The regenerated adsorbents were then tested for the adsorption of calcium and magnesium and the regeneration percentage were calculated based on the comparison of the removal efficiencies of fresh and regenerated adsorbents.

\section{Result and Discussion}

\subsection{Adsorbent Characteristics}

The various physical and chemical characteristics of the AC for both coffee husk and bagasse are represented in table 3.1 .

Table 3.1. Physico-Chemical properties.

\begin{tabular}{lll}
\hline Parameters & ABC & ACHC \\
\hline $\mathrm{pHzpc}$ & 7.58 & 103 \\
$\mathrm{BET}\left(\mathrm{m}^{2} / \mathrm{g}\right)$ & 546.6 & 410 \\
Mesh size & $500 \mu \mathrm{m}$ & $500 \mu \mathrm{m}$ \\
\hline
\end{tabular}

The modified adsorbents were characterized by means of instrumental techniques called Transform Infrared spectroscopy (FTIR) and BET surface area.

The specific surface area of the adsorbents was measured using the BET technique. It showed a significantly higher specific surface area for the ABC and CHC, 546.60 and 410 $\mathrm{m}^{2} / \mathrm{g}$ respectively. The remarkable improvement of the surface area can most likely be attributed to the removal of components occupying the pores of the AC resulting in more accessible pores and consequently larger surface area.

\subsubsection{Infrared Spectral Analysis}

The adsorption of $\mathrm{Ca}$ and $\mathrm{Mg}$ ions on bagasse and coffee husk were also affected by other interactions between functional groups of $\mathrm{Ca}$ and $\mathrm{Mg}$ and bagasse, coffee husk in addition to electrostatic interaction. FTIR analyses were conducted in order to identify possible locations for these interactions. The result is presented in figure 3.1 ( $a$ and $b$ ). As it can be seen, the FTIR spectra of $\mathrm{Ca}$ and $\mathrm{Mg}$ ions, bagasse and coffee husk and after adsorption are discussed below.

\subsubsection{FTIR Spectra of Bagasse}

FTIR spectra of bagasse has a broad band centered between $3154.63 \mathrm{~cm}^{-1}$ and $3334.98 \mathrm{~cm}^{-1}$ ( hydrogen bonded $\mathrm{OH}$ ), the band at 2853.73 to $2954.03 \mathrm{~cm}^{-1}\left(-\mathrm{CH}_{2}\right.$ and $-\mathrm{CH}_{3}$ asymmetric and symmetric stretching), the peak at 1774.54 $\mathrm{cm}^{-1}$ (associated with C-O carbonyl), the peaks at 1590.34 $\mathrm{cm}^{-1}$ and $1462.07 \mathrm{~cm}^{-1}$ (associated with the aromatic ring of lignin) and the large peak at 1022 to $1249.89 \mathrm{~cm}^{-1}$ (associated with the $\mathrm{C}-\mathrm{O}$ bond bending of cellulose). FTIR spectra of SBC show peaks at $3568.37 \mathrm{~cm}^{-1}$. This could be due to $(\mathrm{N}-\mathrm{H}$ stretching), $1590.34 \mathrm{~cm}^{-1}(\mathrm{~N}=\mathrm{N}$ stretching $), 1462.07 \mathrm{~cm}^{-1}$ (aromatic C-C stretching), and $1377.20 \mathrm{~cm}^{-1}$ (S-O bending). 


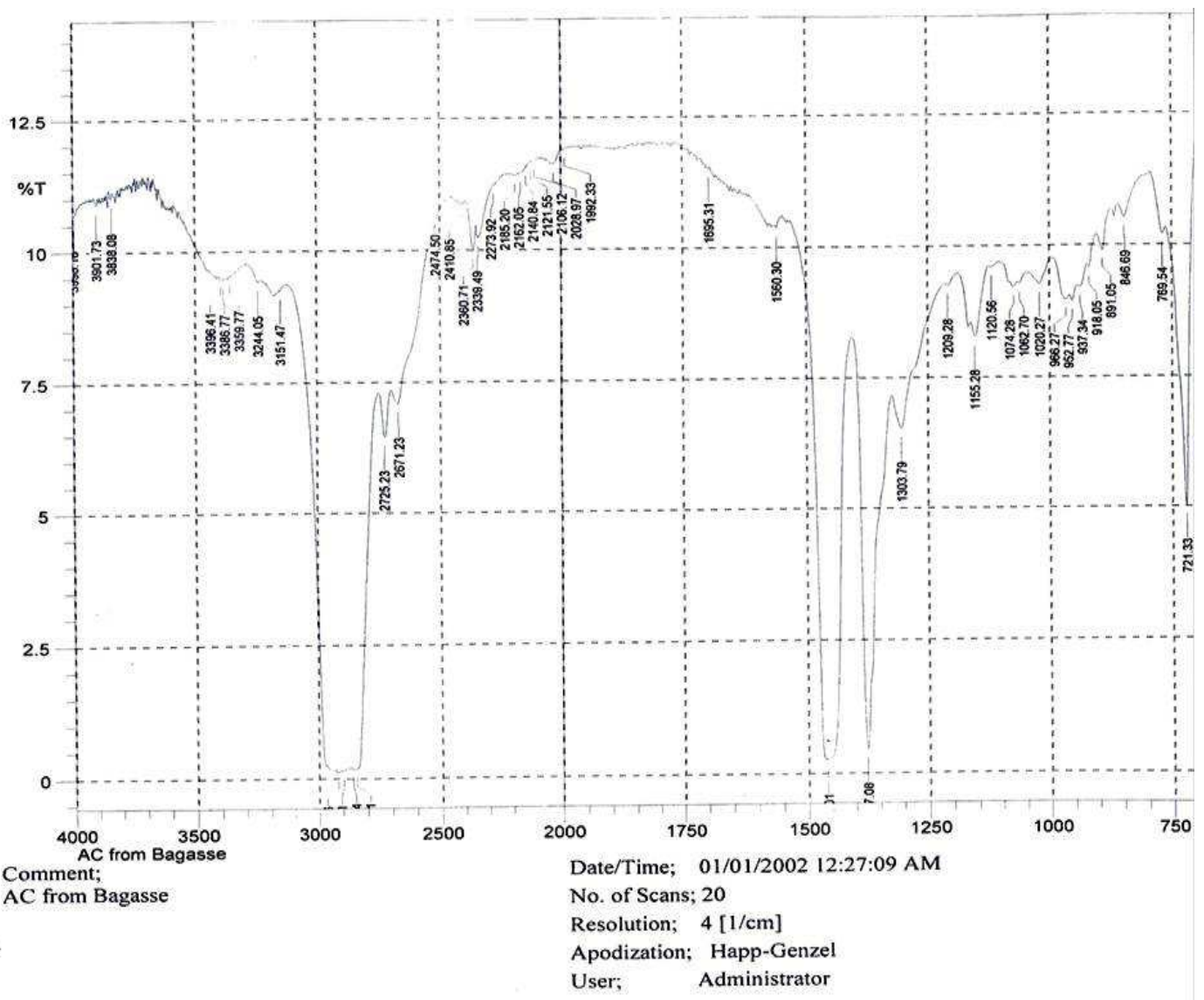

Figure 3.1. (a) FTIR spectral analysis of AC from Sugar cane bagasse.

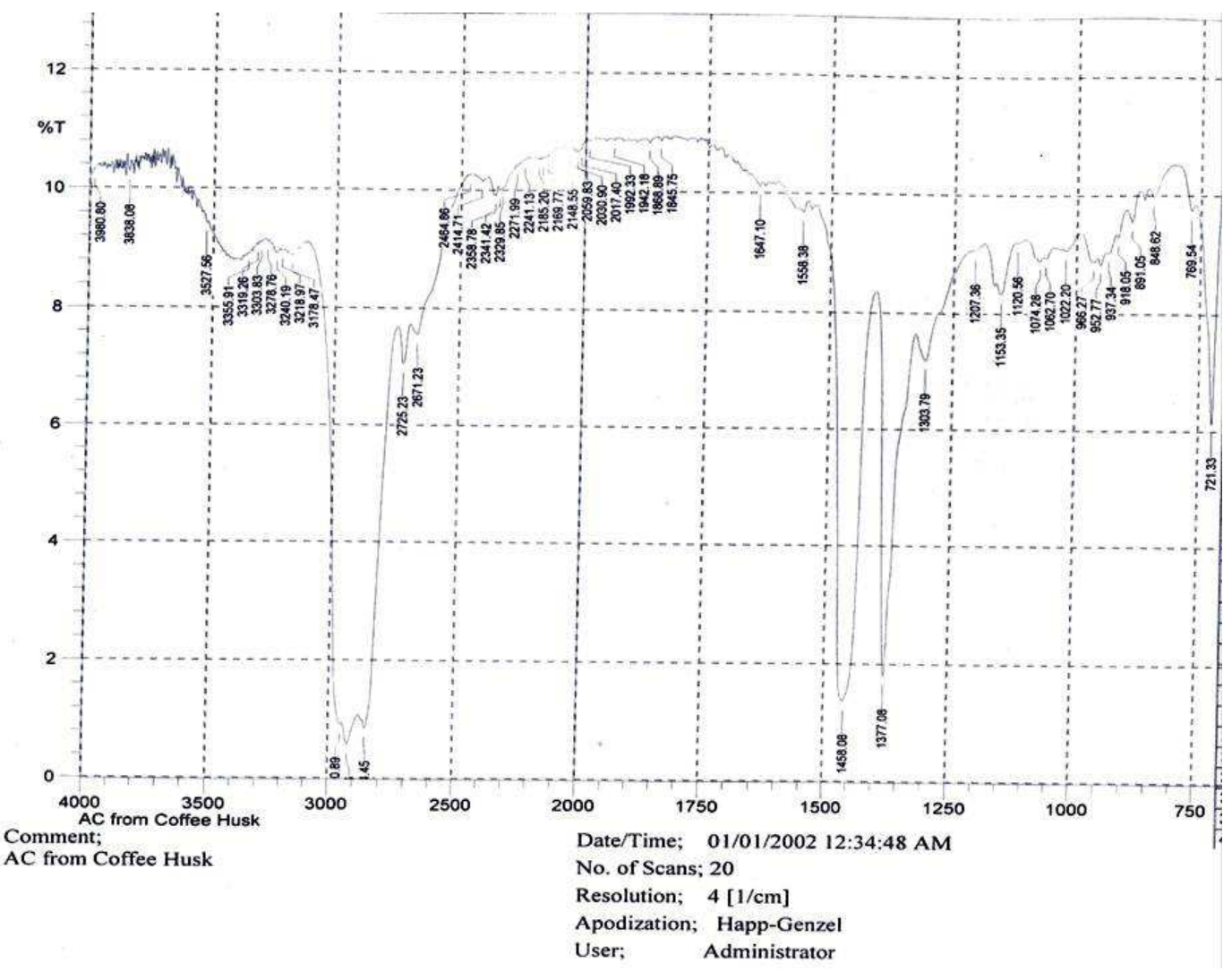

Figure 3.1. (b) FTIR spectral analysis of AC from coffee husk. 


\subsubsection{FTIR Spectral Analysis of Coffee Husk}

The FTIR spectral analysis shows that several functional groups are available on the surface of coffee husk for binding hardness causing agents hardness causing divalent ions. The result was shown in fig 3.2 (b), Wavelengths corresponding to their respective functional groups. Therefore, the wavelengths appeared in the graph i.e. 3431, 2925, 1726, 1652 and 1450 indicates the applicability of $-\mathrm{OH},-\mathrm{CH}, \mathrm{C}=\mathrm{O}$, $\mathrm{C}=\mathrm{C}$, $-\mathrm{COO}$ respectively. The FTIR spectra obtained for the activated coffee husk samples are shown in Fig. 1. The broad band at about $3400 \mathrm{~cm}^{-1}$ included many vibration modes mainly attributed to $-\mathrm{OH}$ groups with a minor contribution of -NH functional groups. The presence of methyl and methylene groups is confirmed by the two sharp peaks at $2925 \mathrm{~cm}^{-1}$ and $2855 \mathrm{~cm}^{-1}$ attributed to asymmetric and symmetric stretching of $\mathrm{C}-\mathrm{H}$ bonds in aliphatic chains.

The peaks located at 1737 and $1633 \mathrm{~cm}^{-1}$ are characteristics of carbonyl group stretching from cellulose and ketones. The presence of -OH group, along with carbonyl group, confirms the presence of carboxylic acid groups in the biosorbent. The peaks at $1508 \mathrm{~cm}^{-1}$ are associated with the stretching in aromatic rings. The peaks observed at 1071 and $1024 \mathrm{~cm}^{-1}$ are due to $\mathrm{C}-\mathrm{H}$ and $\mathrm{C}-\mathrm{O}$ bonds. The $-\mathrm{OH},-\mathrm{NH}$, carbonyl and carboxylic groups are important sorption sites.

\section{2. pH Point of Zero Charge}

The point of zero charge of the adsorbent $\mathrm{ABC}$ and ACHC were assessed from the graph of final $\mathrm{pH}$ versus initial $\mathrm{pH}$ for $0.5 \mathrm{~g}$ of the adsorbents. The results are presented in figure 3.2 ( $a$ and $b$ ). As shown from the graphs, the values of pHpzc of an adsorbent are determined from the points where the initial $\mathrm{pH}$ equals the final $\mathrm{pH}$. The $\mathrm{pHpzc}$ values are 7.50 and 8.103 for $\mathrm{ABC}$ and $\mathrm{ACHC}$ respectively. As presented in the graphs it seems that, the adsorbents were negatively charged at $\mathrm{pH}$ greater than the pHpzc and below pHpzc there was a charge reversal.

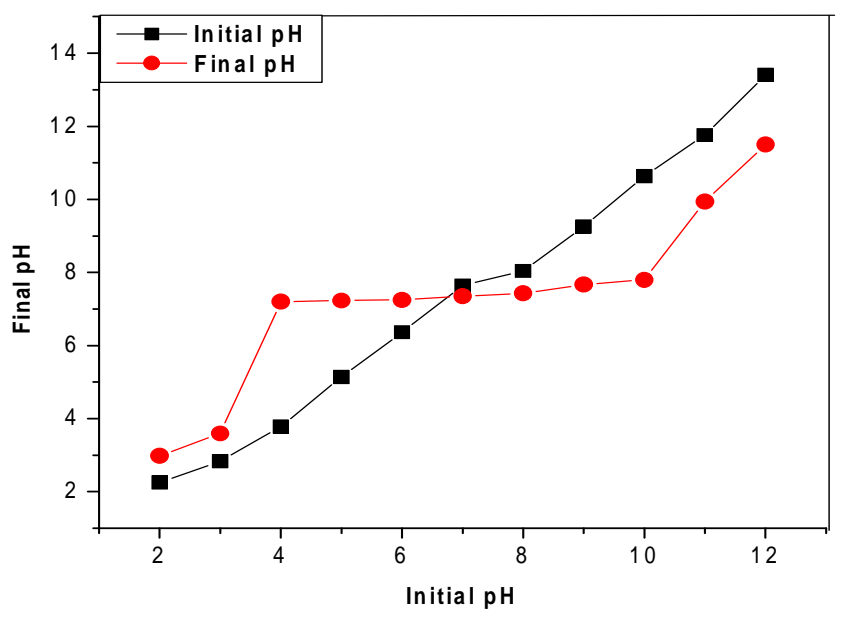

Figure 3.2. (a) pH point zero charge ( $p H p z c)$ for $A B C$.

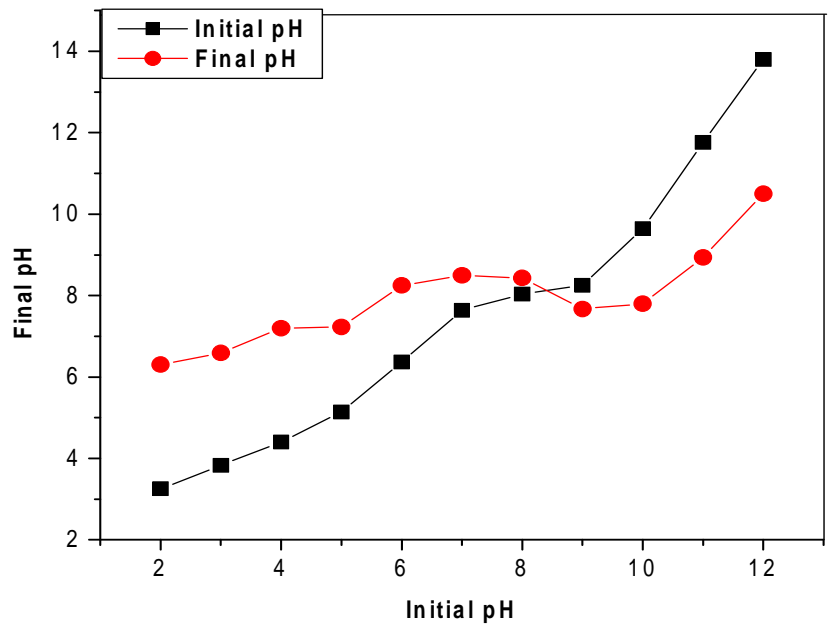

Figure 3.2. (b) pH point zero charge (pHpzc) for ACHC.

It has been reported by earlier researchers that, the pHpzc of an adsorbent increases with increase in basic groups on the surface of the adsorbents [19]. This is due to that, the adsorbents have basic surfaces since the pHpzc values is greater than 7 .

From the results, it can be concluded that alkali modification of the adsorbent gave a negative (basic) surface charge for the adsorbent. The relationship between pHpzc and adsorption capacity is that cations adsorption on any adsorbent will be expected to increase at $\mathrm{pH}$ value higher than the pHpzc while anions adsorption will be favorable at $\mathrm{pH}$ values lower than the pHpzc [21].

\subsection{Batch Activated Carbon Filtration}

In the present study, alkali treated bagasse and coffee husk are used as an adsorbent for water hardness causing constituents from aqueous solutions and polluted water. Based on the results obtained, the effects of these parameters are discussed in the subsequent sections.

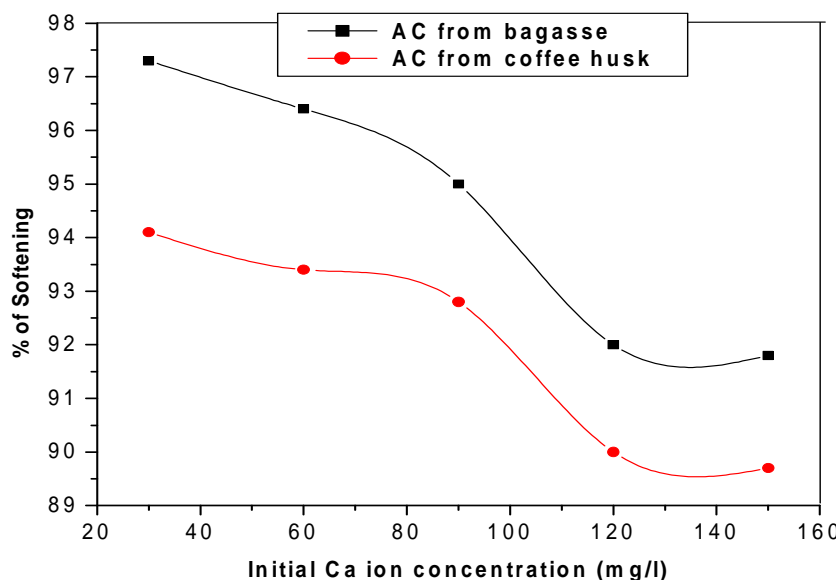

Figure 3.3. Effect of initial Ca hardness concentrations on softening efficiency $(2 \mathrm{~g}$ adsorbent, $\mathrm{pH}$ 6.5, room temperature, agitation speed 200 rpm. 
Effect of the contact time and initial hardness agent concentration: The effects of the initial calcium and magnesium concentrations and the contact time on the softening efficiency of $\mathrm{ABC}$ and $\mathrm{ACHC}$ are illustrated in figure 3.3. As it can be seen, adsorption efficiency was improved by increasing the contact time and decreased by increasing the initial ions concentration.

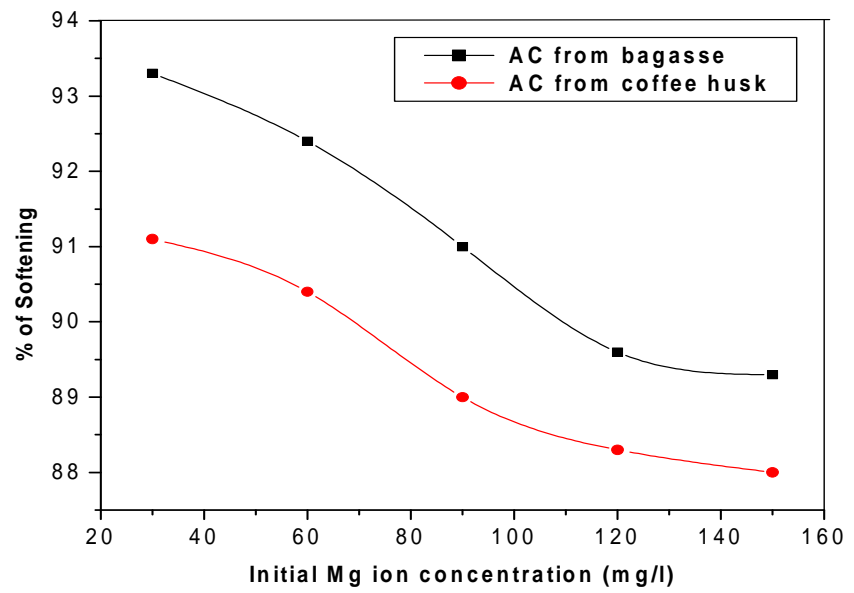

Figure 3.4. (a) Effect of initial Mg ion concentrations on softening efficiency (2 g adsorbent, $\mathrm{pH} 6.5$, room temperature, agitation speed $200 \mathrm{rpm}$.

Accordingly, for an initial metal concentration of 120 $\mathrm{mg} / \mathrm{L}, 97 \%$ and $94.1 \%$ of calcium and $90.8 \%$ and $93.3 \%$ of magnesium were adsorbed by $\mathrm{ABC}$ and $\mathrm{ACHC}$ respectively, showing for both adsorbents a higher affinity for calcium over magnesium. Furthermore, alkali modification of both adsorbents improved the adsorption capacity toward both tested cations.

The effect of contact time on $\mathrm{Ca}$ and $\mathrm{Mg}$ ions was investigated by varying the contact time (30-150 min), while other parameters were kept constant. The result is presented in figure 3.4 and 3.5. As it can be seen in the figure, softening efficiency increased with an increasing in contact time before equilibrium is reached and after equilibrium removal efficiency would be constant.

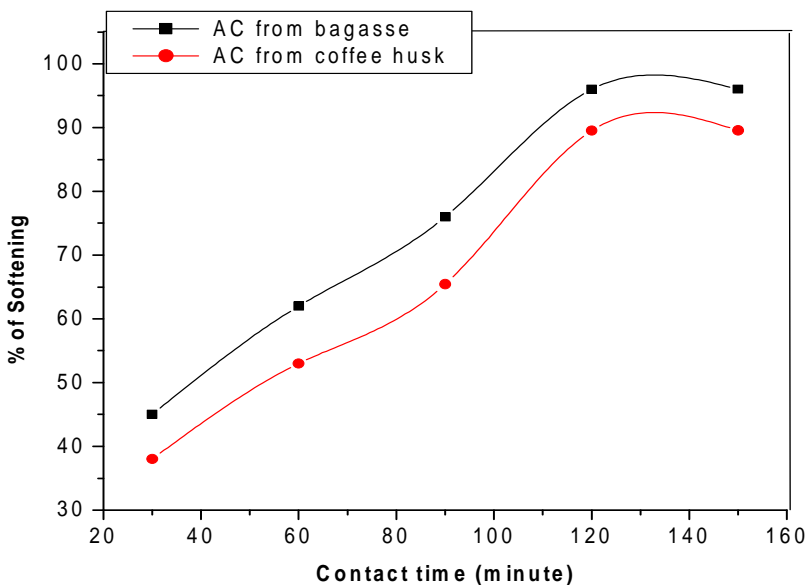

Figure 3.4. (b) Effect of contact time on softening efficiency of calcium hardness $(2 \mathrm{~g} / \mathrm{L}$ adsorbent, $\mathrm{pH} 6.5$, room temperature, agitation speed 200 rpm and at $120 \mathrm{mg} / \mathrm{l}$ initial concentration
The optimum time observed for removal of $96.1 \%$ and $93.4 \%$ of $\mathrm{Ca}$ and $\mathrm{Mg}$ hardness were $120 \mathrm{~min}$. There was no appreciable increase in percentage removal of total hardness after these optimum times. As shown in Figure 3.4(b) and 3.5, the adsorption process took place in two stages. The first stage was rapid. This may be due to that, at the start large number of vacant surface site may be available for adsorption process. The second stage represented a slower progressive adsorption. The reason is that, the remaining vacant surface sites may be exhausted due to repulsive forces between the solute molecules of solid and bulk phase [24],[26]. With the progressive occupation of these sites, the process becomes slower in the second stage. Moreover the initially deposited metal ions penetrate to the interior of the sorbent through intra-particle diffusion which was slower process. This was similar with the observations of other studies [21], [24,].

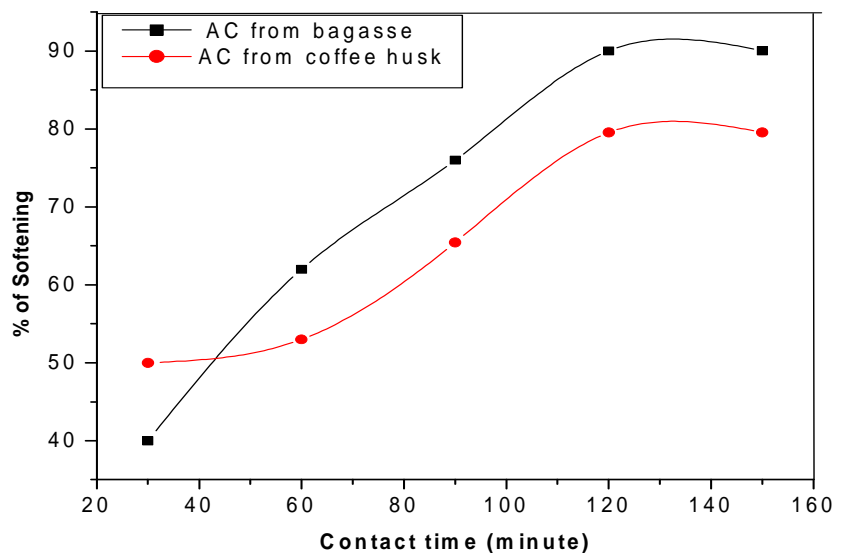

Figure 3.5. Effect contact time on softening efficiency of magnesium hardness (2 g/L adsorbent, pH 6.5, room temperature, agitation speed 200 rpm, $120 \mathrm{mg} / \mathrm{l}$.

Surface adsorption and ion exchange can be considered as the driving forces of ion removal. While bonding of metal ions to the surface can be considered as the main mechanism responsible for metal uptake by natural pumice, in addition to surface adsorption, ion exchange can also be involved in the case of the alkali-modified pumice leading to a remarkable enhancement of the adsorption capacity [19]. Furthermore, alkali modification can contribute to the removal of impurities, which can unblock some pores improving accessibility to the active adsorption and ion exchange sites of the modified sample. Removal efficiency also showed an increase with the initial metal concentration, which can be attributed to an increase of the concentration gradient increasing the driving force [24].

Effect of the $\mathrm{pH}$ and the adsorbent mass: The $\mathrm{pH}$ of the solution should be considered as an important factor affecting metal adsorption process due to its impact on the degree of ionization of metal specie and the surface charge of the adsorbent. The effect of $\mathrm{pH}$ of the reaction mixture on the adsorption efficiency at various adsorbent doses was examined in order to optimize the adsorbent dosage and the $\mathrm{pH}$. According to the results summarized in fig 3.6 and 3.7, the highest adsorption capacity towards $\mathrm{Ca}^{+2}$ and $\mathrm{Mg}^{+2}$ ions 
was achieved at $\mathrm{pH}=6.5$ for $\mathrm{ABC}$ and $\mathrm{ACHC}$ and for all tested dosages. This optimal $\mathrm{pH}$ was in accordance with the zero point charge values (6.50 and 8.310 for $\mathrm{ABC}$ and $\mathrm{ACHC}$ respectively).

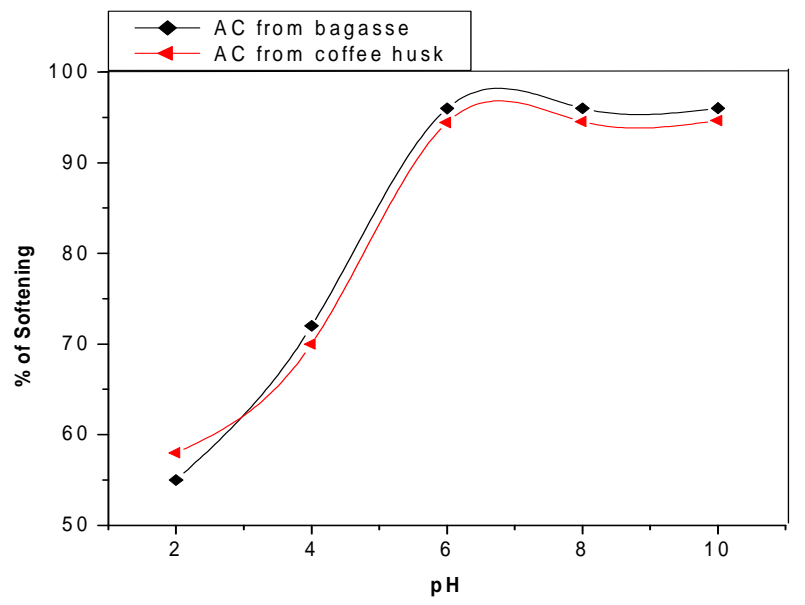

Figure 3.6. Effect of $\mathrm{pH}$ on softening of calcium hardness (contact time 120 min, ions concentration $120 \mathrm{mg} / \mathrm{L}$, room temperature, $200 \mathrm{rpm}$ agitation).

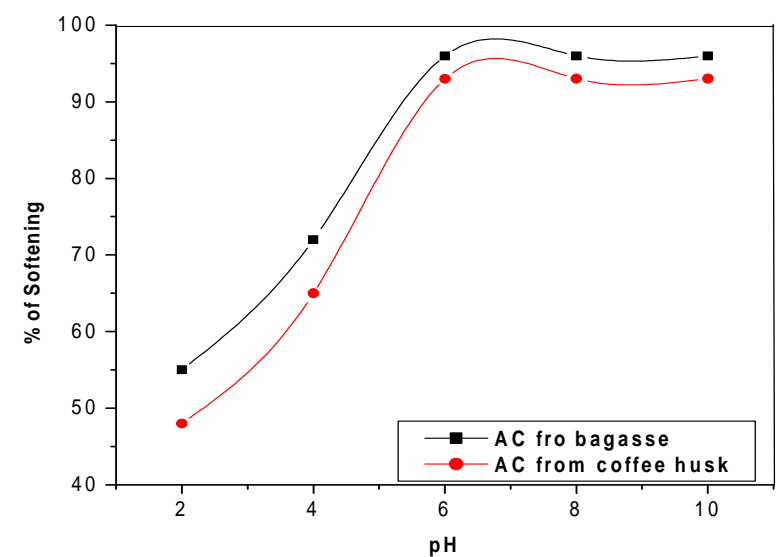

Figure 3.7. Effect of pH on softening of magnesium hardness (contact time $120 \mathrm{~min}$, ions concentration $120 \mathrm{mg} / \mathrm{L}$, room temperature, $200 \mathrm{rpm}$ agitation).

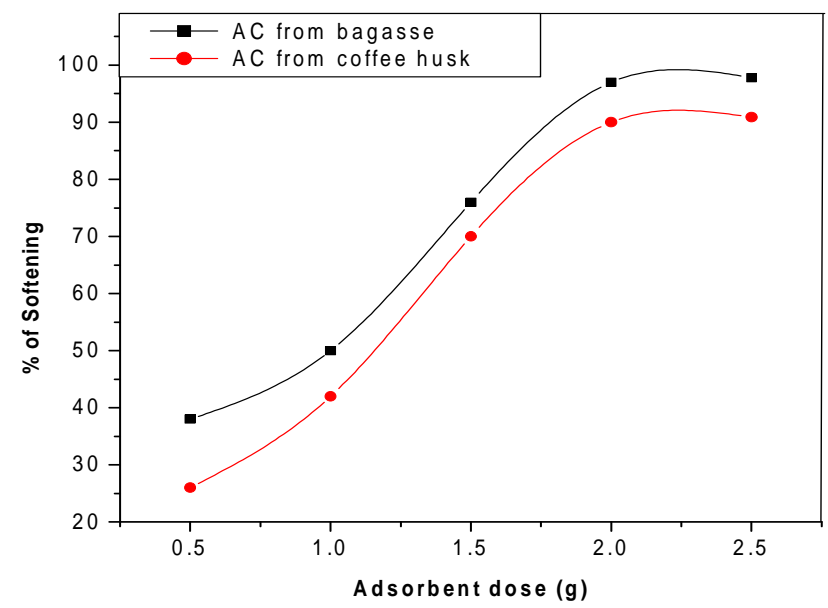

Figure 3.8. Effect of adsorbents dose on softening of calcium hardness (contact time $120 \mathrm{~min}$, ions concentration $120 \mathrm{mg} / \mathrm{L}$, room temperature, 200 rpm agitation).
The removals of water hardness causing constituents by $\mathrm{ABC}$ and $\mathrm{ACHC}$ at different dose $(0.5-2.5 \mathrm{~g})$ for the constant $\mathrm{Ca}$ and $\mathrm{Mg}$ concentration of $120 \mathrm{mg} / \mathrm{l}$ are investigated. Results are presented in figure 3.8 and 3.9. The percentage removal of $\mathrm{Ca}$ and $\mathrm{Mg}$ increases from 37.0 to $96.2 \%$ with an increase in the activated bagasse and coffee husk carbon amount from 0.5 to $2.5 \mathrm{~g}$ respectively. This is due to the increasing of the adsorption sites available for adsorption.

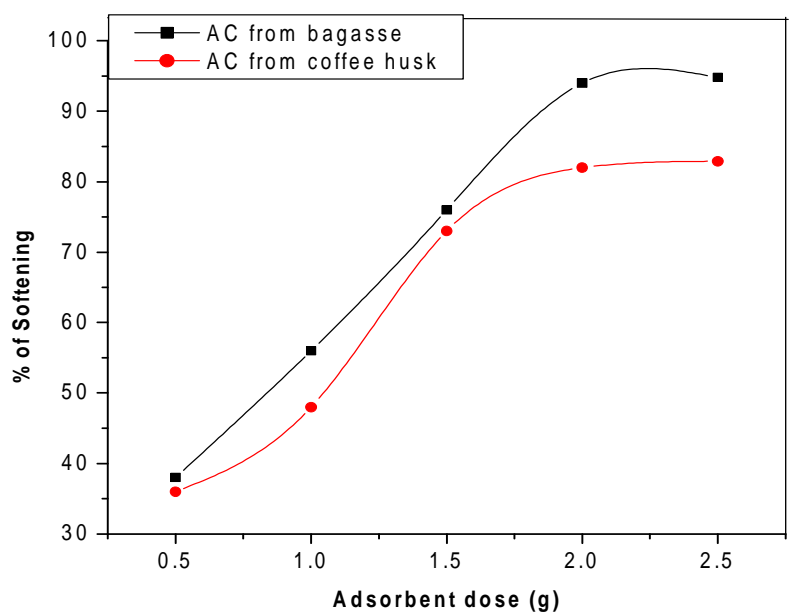

Figure 3.9. Effect of adsorbent dose on softening of magnesium hardness (contact time $120 \mathrm{~min}$, ions concentration $120 \mathrm{mg} / \mathrm{L}$, room temperature, 200 rpm agitation).

As it shows in fig 3.6 and 3.7 of the $\mathrm{pH}, 79$ and $96 \%$ of calcium and 51 and $93 \%$ of magnesium were removed by 2 $\mathrm{g} / \mathrm{L}$ of the $\mathrm{ABC}$ and $\mathrm{ACHC}$ adsorbents, respectively. The lower removal efficiencies observed in acidic medium (i.e. $\mathrm{pH}$ in the range 2-5) can be attributed to the protonation of adsorbent functional groups or competition of $\mathrm{H}^{+}$with metal ions to bind and occupy the active sites of the adsorbents. On the other hand, in alkaline environment (i.e. $\mathrm{pH}$ in the range 7-10), the formation of metal hydroxide can be considered as the main reason for decreasing metal uptake. Similar results were reported [26]. The highest removal capacity at $\mathrm{pH}=7.5$, namely close to the zero point charges of both adsorbents, confirms that the studied adsorbents can be considered as promising low cost adsorbents suitable for the softening of hardness ions from drinking water.

The linear increase of the adsorption capacity for increasing adsorbent dosage indicated the accessibility of a larger number of sorption sites at higher dosage to adsorb calcium and magnesium ions. Contrarily, in the removal of calcium using raw and modified sugar cane bagasse, adsorption capacity remained constant above $100 \mathrm{mg}$ adsorbent.

Effect of the temperature: The temperature effect in the range of $10{ }^{\circ} \mathrm{C}$ to $60{ }^{\circ} \mathrm{C}$ was studied and thermodynamic parameters were calculated. As shown in Fig 3.10, while the effect of temperature on magnesium adsorption seemed to be negligible, a low maximum for the adsorption of calcium was absorbed at $20^{\circ} \mathrm{c}$. 


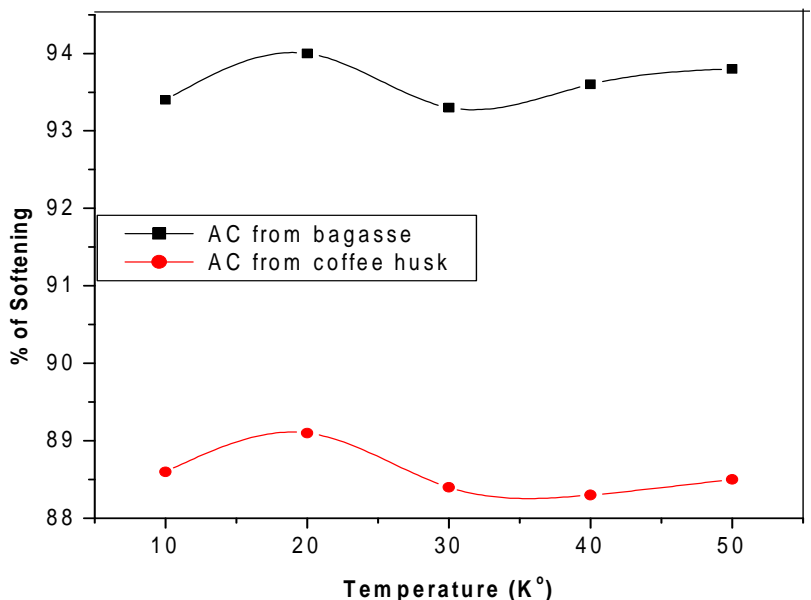

Figure 3.10. Effect of temperature on softening of Calcium hardness (contact time $120 \mathrm{~min}$, ions concentration $120 \mathrm{mg} / \mathrm{L}, 2 \mathrm{~g}$ adsorbents, 200 rpm agitation).

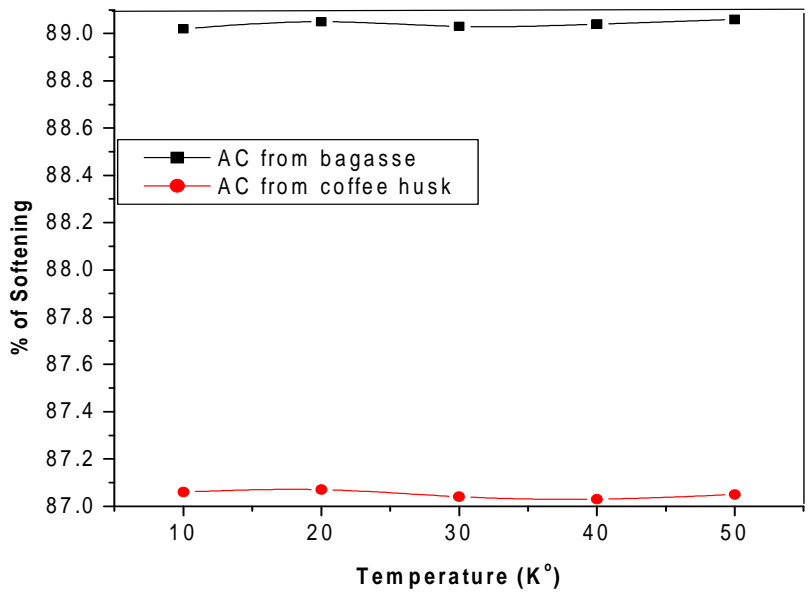

Figure 3.11. Effect of temperature on softening of magnesium hardness.

\subsection{Regeneration of the Saturated Adsorbents}

Regeneration experiments were conducted to study the reusability of the spent adsorbents, which is a very important parameter in terms of economic feasibility of the developed process. Regeneration using sulphuric acid solution was carried out on the spent bagasse and coffee husk samples. As it were shown in the figure below, maximum recovery of the adsorbed calcium and magnesium was achieved in less than 200 minutes leading to 78 and $73 \%$ desorption of the adsorbed calcium and magnesium at 97 and $93 \%$ of the adsorbed calcium and magnesium from $\mathrm{ABC}$ and $\mathrm{ACHC}$ respectively. Furthermore, maximum cation desorption for saturated carbon were observed after $300 \mathrm{~min}$ of regeneration, while only $200 \mathrm{~min}$ of regeneration was needed to achieve maximum cation desorption of the saturated modified adsorbent. It should be noticed that even if the modified sugar cane bagasse showed higher sorption capacity for calcium and magnesium rather than modified coffee husk, its regeneration potential was lower than that of the activated carbon from bagasse.

Generally, $\mathrm{Ca}$ and $\mathrm{Mg}$ recovery and adsorbent regeneration under 8 cycles of adsorption and desorption (n) are presented in fig 3.12 and 3.13. As the $n$ increased, the percentage of $\mathrm{Ca}$ and $\mathrm{Mg}$ recovered and adsorbent regeneration and also $\mathrm{Ca}$ and $\mathrm{Mg}$ removal, until 4 of these cycles slightly decreased and after that, until 8 , sharply decreased. It is shown that $\mathrm{ABC}$ and $\mathrm{ACHC}$ can be reused for softening/regeneration processes; but after that, it loses its softening/regeneration ability and its performance drops down.

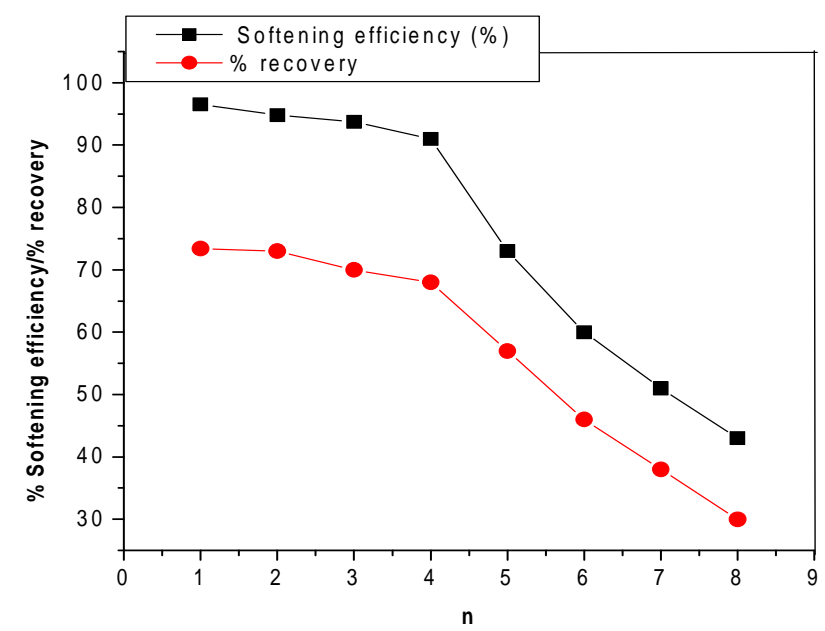

Figure 3.12. Successive softening/regeneration efficiency of Ca hardness.

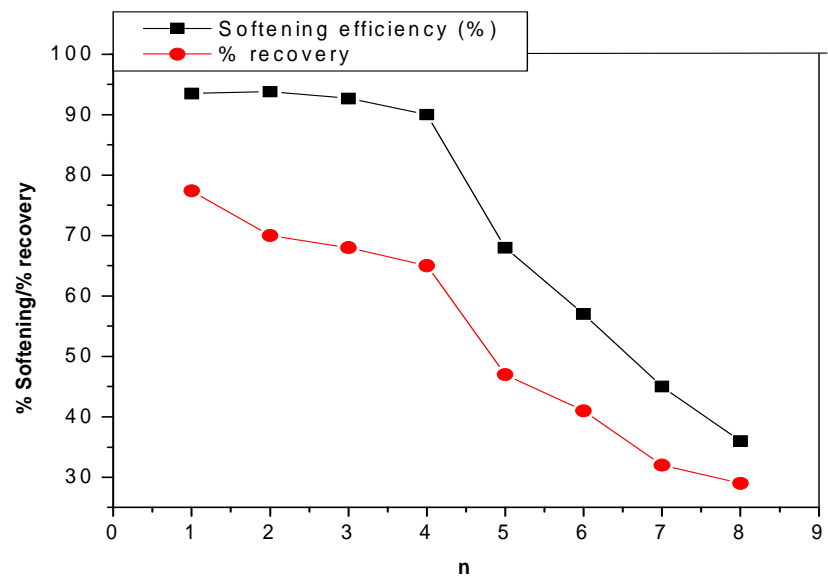

Figure 3.13. successive softening/regeneration efficiency of $\mathrm{Mg}$ hardness.

\section{Conclusion}

Softening of hard water by removing $\mathrm{Ca}^{2+}$ and $\mathrm{Mg}^{2+}$ cations was studied using alkali-modified sugar cane bagasse and coffee husk as adsorbents. Increasing the mass of adsorbent, the contact time and decreasing the initial ions concentration leads to an increase of cations removal. The studied adsorbents showed a higher selectivity for calcium adsorption if compared to magnesium in $\mathrm{ABC}$ than ACHC. Both adsorbents are efficient to adsorb water hardness causing constituents; but, ABC is more critical than ACHC. After treating synthetic water solution simulating an actual water stream with the alkali modified activated bagasse and activated coffee husk, total hardness of the treated sample met the required standard for drinking water. 


\section{Acknowledgement}

This paper was sponsored by Jigjiga University under Research and Community Service Directorate as part of the 2014 funded proposal. I am grateful to Haramaya University and Ethiopian pharmaceutical factory for their cooperation in AAS and FTIR analysis and characterization respectively.

\section{References}

[1] AWWA, Standard Methods for the Examination of Water and Wastewater, 20th ed., Washington, DC, 2005.

[2] O.K. Jinior, L.V.A. Gurgel, L.F. Gil, Removal of $\mathrm{Ca}(\mathrm{II})$ and $\mathrm{Mg}$ (II) from aqueous single metal solutions by mercerized cellulose and mercerized sugarcane bagasse grafted with EDTA dianhydride (EDTAD), Carbohydr. Polym. 79 (2010) 184-191.

[3] A. Zuorro, R. Lavecchia, S. Natali, Magnetically modified agro-industrial wastes as efficient and easily recoverable adsorbents for water treatment; chemical engineering transactions Vol. 38, 2014.

[4] Ami Cobb, Low-Tech Coconut Shell Activated Charcoal Production, International Journal for Service Learning in Engineering Vol. 7, No. 1, pp 93-104, (2012).

[5] D. Bruggen, C. Vandecasteele, Removal of pollutants from surface water and groundwater by nano filtration: Overview of possible applications in the drinking water industry, Environ. Pollut. 122 (2003) 435-445.

[6] M.R. Teixeira, M.J. Rosa, The impact of the water background inorganic matrix on the natural organic matter removal by nanofiltration, J. Membr. Sci. 279 (2006) 513-520.

[7] M. Yan, D. Wang, J. Ni, J. Qu, Y. Yan, C.W.K. Chow, Effect of polyaluminum chloride on enhanced softening for the typical organic-polluted high hardness North-China surface waters, Sep. Purif. Technol. 62 (2008) 401-406.

[8] K. Suzuki, Y. Tanaka, T. Osada, M. Waki, Removal of phosphate, magnesium and calcium from swine wastewater through crystallization enhanced by aeration, Water Res. 36 (2002) pp 2991-2998.

[9] A. Dimirkou, M.K. Doula, Use of clinoptilolite and an Feoverexchanged clinoptilolite in $\mathrm{Zn}^{2+}$ and $\mathrm{Mn}^{2+}$ removal from drinking water, Desalination. 224 (2008) 280-292.

[10] R. Sheikholeslami, Composite scale formation and assessment by the theoretical Scaling Potential Index (SPI) proposed previously for a single salt, Desalination 278 (2011) 259-267.

[11] L. Fu, J. Wang, Y. Su, Removal of low concentrations of hardness ions from aqueous solutions using electrodeionization process, Sep. Purif. Technol. 68 (2009) 390-396.

[12] J.S. Park, J.H. Song, K.H. Yeon, S.H. Moon, Removal of hardness ions from tap water using electromembrane processes, Desalination 202 (2007) 1-8.
[13] S.J. Seo, H. Jeon, J.K. Lee, G.Y. Kim, D. Park, H. Nojima, J. Lee, S.H. Moon, Investigation on removal of hardness ions by capacitive deionization (CDI) for water softening applications, Water Res. 44 ( 2010 ) 2267-2275.

[14] C.W. Li, J.C. Liao, Y.C. Lin, Integrating a membrane and a fluidized pellet reactor for removing hardness: effects of NOM and phosphate, Desalination 175 (2005) 279-288.

[15] J.N. Apell, T.H. Boyer, Combined ion exchange treatment for removal of dissolved organic matter and hardness, Water Res. 44 (2010) 2419-2430.

[16] H. Faghihian, M.G. Maragheh, H. Kazemian, The use of clinoptilolite and it's sodium form for removal of radioactive caesium, and strontium from nuclear wastewater and $\mathrm{Pb}^{++}$, $\mathrm{Ni}^{++}, \mathrm{Cd}^{++}, \mathrm{Ba}^{++}$from municipal wastewater, Appl. Radiat. Isot. 4 (1999) pp 655-661.

[17] H. Kazemian, H. Modarres, H.G. Mobtaker, Evaluating the performance of an Iranian natural clinoptilolite and its synthetic zeolite $\mathrm{P}$ for removal of Cerium and Thorium from nuclear wastewaters, J. Radioanal. Nucl. Chem. 258 (2003) $551-556$

[18] Seifi et al. Adsorption of BTEX on surfactant modified granulated natural zeolite nanoparticles: parameters optimizing by applying Taguchi experimental design method, Clean-Soil, Air, Water, 39 (2011) pp 939-948.

[19] Sepehr et, al. (2013) Removal of hardness agents, calcium and magnesium, by natural and alkaline modified pumice stones in single and binary systems, Applied Surface Science, pp 295305, Vol. 03 (42)

[20] N. Feng, X. Guo, S. Liang, Y. Zhu, J. Liu, Biosorption of heavy metals from aqueous solutions by chemically modified orange peel, J. Hazard. Mater. 185 (2011) 49-54.

[21] B. Ersoy, A. Sariisik, S. Dikmen, G. Sariisik, Characterization of acidic pumice and determination of its electrokinetic properties in water, Powder Technol. 197 (2010) 129-135.

[22] B. Ozturk, Y. Yildirim, Investigation of sorption capacity of pumice for $\mathrm{SO}_{2}$ capture, Process Saf. Environ. Prot. 86 (2008) 31- 36 .

[23] M.R. Panuccio, A. Sorgona, M. Rizzo, G. Cacco, Cadmium adsorption on vermiculite, zeolite and pumice: Batch experimental studies, J. Environ. Manage. 90 (2009) 364-374.

[24] F. Akbal, Sorption of phenol and 4-chlorophenol onto pumice treated with cationic surfactant, J. Environ. Manage. 74 (2005) 239-244.

[25] H. Kazemian, M.H .Mallah, Elimination of $\mathrm{Cd}^{2+}$ and $\mathrm{Mn}^{2+}$ from Wastewaters Using Natural Clinoptilolite and Synthetic Zeolite-P, Iran. J. Chem. Chem. Eng. 25 (2006) 91-94.

[26] F. Gode, E. Moral, Column study on the adsorption of $\mathrm{Cr}(\mathrm{III})$ and $\mathrm{Cr}(\mathrm{VI})$ using Pumice, Yarıkkaya brown coal, Chelex-100 and Lewatit MP 62, Bioresour. Technol. 99 (2008) 19811991. 